\title{
Electrochemical batteries for smart grid applications
}

\author{
Surender Reddy Salkuti \\ Department of Railroad and Electrical Engineering, Woosong University, Daejeon, Republic of Korea
}

\begin{tabular}{l} 
Article Info \\
\hline Article history: \\
Received Oct 19, 2019 \\
Revised Dec 9, 2020 \\
Accepted Dec 21, 2020 \\
\hline
\end{tabular}

\section{Keywords:}

Battery energy storage

Electric vehicles

Electrochemical storage

Rechargeable batteries

Renewable energy resources

\begin{abstract}
This paper presents a comprehensive review of current trends in battery energy storage systems, focusing on electrochemical storage technologies for smart grid applications. Some of the batteries that are in focus for improvement include Lithium-ion, metal-air, Sodium-based batteries and flow batteries. A descriptive review of these batteries and their sub-types are explained along with their suitable applications. An overview of different types and classification of storage systems has been presented in this paper. It also presents an extensive review on different electrochemical batteries, such as lead-acid battery, lithium-based, nickel-based batteries and sodium-based and flow batteries for the purpose of using in electric vehicles in future trends. This paper is going to explore each of the available storage techniques out there based on various characteristics including cost, impact, maintenance, advantages, disadvantages, and protection and potentially make a recommendation regarding an optimal storage technique.
\end{abstract}

This is an open access article under the CC BY-SA license.

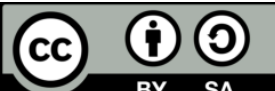

\section{Corresponding Author:}

Surender Reddy Salkuti

Department of Railroad and Electrical Engineering

Woosong University

171 Dongdaejeon-ro (155-3 Jayang-dong), Dong-gu, Daejeon, 34606-Republic of Korea

Email: surender@wsu.ac.kr

\section{INTRODUCTION}

Recently all the governments are working towards to substantially expand the share of renewable energy in global energy market. The optimal inclusion and coordination of renewable energy resources (RERs) like wind, bioenergy, solar, geothermal with thermal units can minimize the traditional fossil fuel consumption and can effectively reduce the harmful emissions from fossil fuel generating units around $20-40 \%$. Governments are giving incentives to manufacturers to inverst in developing electric vehicles, and its main components such as electric motors and lithium-ion batteries. After that more work is being done to increase the assimilation of various energy storage methods into the existing or smart grids which are connected to RERs. This is mainly due to the uncertainty that arises with these RERs. Energy storage has become an important component of advanced electrical systems along with RERs [1]. The electricity demand fluctuates constantly on several factors, for example, a house will require more energy on a hot day to run fans and AC's to cool the home or when hosting guests, while a factory will require more energy for production in periods of peak demand for their goods. On the other hand, factors such as presence of cloud cover and fluctuation of wind supply will significantly effect the power obtained from solar and wind energy systems [2].

Energy can be easily accessed by the conversion or breakdown of carbon-based life or hydrocarbon based fuels directly, but as the demands of the energy-based sector increases, it seems much more viable if energy can be stored or collected to be used later with ease, which is considered as energy storage systems (ESS). ESS can be divided into further categories such as mechanical, electrical, thermal and electrochemical (battery) energy storage systems. However, the main focus of present paper is on electrochemical energy storage technologies. Currently, the electrochemical energy storage can provide a various range of 
applications from powering miniature electronic systems to providing support in electrifying major portions of the electrical grid [3]. Various distributed generation sources available in the system includes small hydro, wind, biomass, solar PV, fuel cells and gas or diesel cogeneration. The main application of energy storage is to work coordinately with the available distributed generation to make the power system generation adequacy. Power electronic concepts play an important role in battery systems for charging, balancing, and estimation of parameters and in determining an equivalent circuit for a battery cell.

Conventional grid faces huge demands based on various loads dependent on factors like time of the day, seasons, or availability of natural fuel resources. This dependence causes reliability issues when there is a high demand and low generation. The energy storage technologies in the form of batteries, can be used to meet the peak demand of the grid by providing electricity as an ancillary storage systems, in addition to the already present renewable storage systems [4]. Most important challenges is to develop robust and highenergy Lithium/air storage batteries which suggests the future research scope to overcome and understand these difficulties have been discussed in Reference [5]. A comprehensive overview of challenges and recent developments in electrolyte research and development, especially for rechargeable batteries, supercapacitors, redox flow batteries has been presented in [6].

Integration of large scale storage systems with wind and solar PV plants is one of the possible and widely adopted solution to mitigate the large fluctuations in power generation by fast charging or discharging of storage battery. The energy storage system is used to make solar PV and wind powers scheduable/dispatchable by mitigating the short-term power fluctuations due to the movement of clouds and wind speeds [7]. The main objective of present paper is to present the classification of energy storage systems and to review various electrochemical batteries. The remainder of the present paper is organized as follows: The classification of various energy storage approaches is discussed in section 2 . On the other hand, section 3 presents the review of different electrochemical batteries. At last, the conclusion is drawn in section 4.

\section{CLASSIFICATION OF ENERGY STORAGE TECHNOLOGIES}

Battery models play a vital role in predicting the performance of battery, battery pack sizing and in designing the controls for battery management. As mentioned earlier, the ESSs can be divided into electrical, mechanical, electrochemical (battery) and thermal energy storage systems, and they are [8]:

a. Mechanical energy storage technology: It is further categorized based on

- Potential energy storage systems (such as pumped hydroelectric storage and compressed air energy storage)

- Kinetic energy storage (such as flywheels) [9]

b. Electrical energy storage technology: It is further categorized based on

- Current/Magnetic energy storage (such as super conducting magnetic energy storage)

- Electrostatic energy storage (such as supercapacitors and capacitors)

c. Electrochemical energy storage technology: It is further categorized based on

- Chemical energy storage systems (such as molten carbonate fuel cells, metal air batteries and fuel cells)

- Electrochemical storage (such as rechargeable batteries) [10]

d. Thermal energy storage technology: It is further categorized based on

- High temperature ESSs (such as hot rocks, hot water accumulators, concrete and graphite)

- Low temperature ESSs (such as cryogenic ESS and auriferous cold energy storage).

Battery storage systems store electricity in chemical energy form and they are among the oldest methods of storing electricity. A battery comprises of 3 parts: a cathode (i.e., negative electrode), an anode (i.e., positive electrode), and an electrolyte (liquid or solid). The battery reactions are reversible, during the discharge an electrochemical reactions occur at electrodes which generate electron flow through the external circuit [11]. Similarly, for recharging of a battery, a voltage across electrodes is applied externally. Batteries are applicable in wide range including electric vehicles (EVs), renewable energy storage (RES) systems, electronic devices, and uninterruptible power supply [12].

\section{REVIEW OF ELECTROCHEMICAL BATTERIES}

Energy storage systems (ESSs) are very important to the operation of electrical power systems. ESSs are being established as an important component of modern power systems along with the RERs. The main application of distributed energy storage is to coordinate the distributed generation to enable generation adequacy [13]. Generally, secondary/rechargeable batteries are used for large scale ESSs. These include leadacid, metal-air, zinc-bromide, lithium-ion batteries. Various battery storage systems are one of the widely used options for storing the surplus power from rthe RERs and aslo discharging during the power shortage situation [14]. Batteries available for EVs include nickel-metal hydride batteries, lithium-ion batteries, 
ultracapacitors and lead-acid batteries. However, accurately modeling battery performance is tricky because the choice of model parameters and the number of variables involved creates a complex problem. Traditional algorithms developed for battery model parameterization can produce suboptimal results.

\subsection{Lithium (Li)-ion batteries}

With ever increasing gas prices and over-reliance on crude oil, there has been a greater demand for electric vehicles (EVs) which also provide an avenue to reduce the carbon footprint. EVs are built to utilize lithium-ion batteries which are charged up by plugging into electrical outlets [15]. Although, electrical energy does not last for more than fractions of seconds when produced, the lithium-ion batteries store energy which can be used to power the vehicle over a range. However, the main limitation with this method is the excessive cost which has hindered consumers from embracing it as projected. Li-ion battery costs are projected to fall to $\$ 397 / \mathrm{kWh}$ by 2020 , but this is nowhere close to the $\$ 150 / \mathrm{kWh}$ price target level which will make it a viable option for the masses [16]. Some ways to approach reduce the cost of these batteries include:

- Finding a better material and cost-effective scale to produce the battery (packs)

- Improving cathode voltage and capacity

- $\quad$ Finding other suitable technologies such as Lithium-air and Magnesium-ion, which may prove cheaper alternatives.

Containerized Li-ion battery ESSs are used in this battery energy storage plant. Various battery energy storage modules are connected in series according to the required DC voltage [17]. A lux research report recently stated that the target will likely be missed, with costs expected to fall to only about $\$ 397 / \mathrm{kWh}$ $[18,19]$. It is important to know that rate of discharge of battery as well as the charge time of batteries is generally the leak stored energy after the charging [20]. The schematic view of Li-ion battery is depicted in Figure 1 [21].
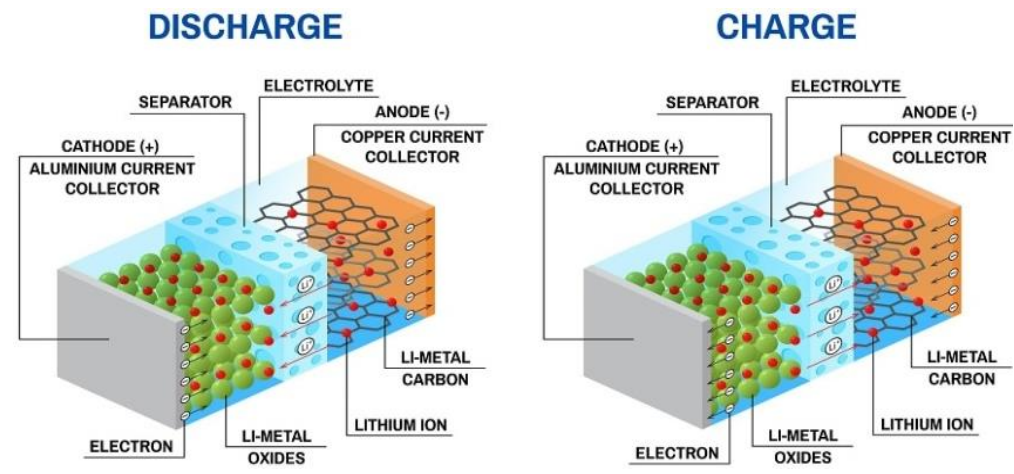

Figure 1. Schematic view of lithium-ion battery

The advantages of these batteries include: they can be made in different sizes and shapes to meet various needs, no memory effect, low self-discharge rate, lighter weight in comparison to other equivalent secondary cells, and it is relatively safe for the environment, and helps to reduce carbon emissions from vehicles. Whereas, the disadvantages include elevated temperatures and high charge levels hasten capacity loss, possess relatively high internal resistance which also increases with aging, and making this storage method cost-effective and developing all the related technologies has proved a challenge and must be addressed before it can be widely accepted [22].

\subsection{Lead-acid batteries}

These are one of the oldest and widely used batteries. They are used in several applications including cars and electronic devices. They are quite inexpensive and efficient. Lead acid batteries come in two styles, sealed and refillables. The sealed types are virtually maintenance free while the electrolyte levels of the refillables have to be monitored. A lead-acid battery, a voltage is produced when reaction occurs between the lead electrodes and sulfuric acid and water electrolytes [23]. The schematic view of lead-acid battery is depicted in Figure 2. Various capacity parameters of lead-acid batteries are: energy density is $60-75 \mathrm{Wh} / 1$, specific energy is $30-40 \mathrm{Wh} / \mathrm{Kg}$, charge/discharge efficiency is $50-92 \%$, specific power is $180 \mathrm{~W} / \mathrm{kg}$, self discharge rate is $3-20 \% /$ month, cycle durability is $500-800$ cycles and nominal cell voltage is $2.105 \mathrm{~V}$ [24]. Applications of these batteries include lead-acid batteries are automobile industry, UPS, communication systems and substation reserve power [25]. 


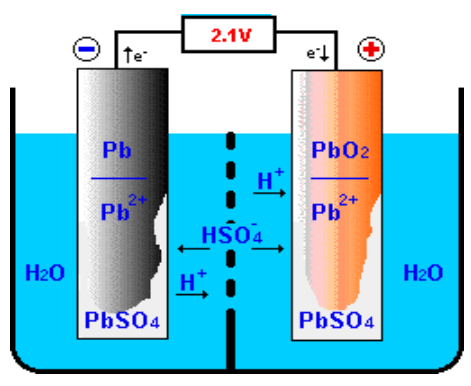

Figure 2. Schematic diagram of lead-acid battery

The cost of lead-acid battery is $\$ 0.17 / \mathrm{Wh}$. Lead-acid batteries pose a huge environmental concern due to the toxicity. However, when maintained and handled with caution, these risks can greatly be reduced. There are also many recycling facilities that can reuse the components of the lead batteries [26]. The risks of environmental contamination can be greatly controlled through proper disposal of the batteries. These batteries are inexpensive, ready amiability and mature technology. However, the disadvantages include short cycle life, low specific energy and power, short cycle life, and high maintenance [27].

\subsection{Nickel-based batteries}

These batteries include nickel metal hydride (NiMh) battery and nickel-cadmium (NiCd) battery. They are described next:

\subsubsection{Nickel metal hydride (NiMh) battery}

NiMH battery is a secondary battery/rechargeable battery where the reactions are reversible. The negative electrode used in nickel metal hydride battery is metal hydride, the positive electrode used is nickel oxyhydroxide $\left[\mathrm{NiO}(\mathrm{OH})_{2}\right]$ and the electrolyte used in potassium hydroxide $[\mathrm{KOH}]$. The anode is made up of metal hydride, where the metal hydride is an alloy of either zinc, vanadium, chromium and titanium. The cathode is made up of nickel oxyhydroxide [28]. The cell reactions are reversible reactions. The reactions occurring at anode are the metal hydride $\left[\mathrm{MH}_{2}\right]$ here undergoes oxidation in the presence of electrolyte $\left[2 \mathrm{OH}^{-}\right]$to give the respective metal and water and electrons, i.e., $2 \mathrm{H}_{2} \mathrm{O}$ and $2 \mathrm{e}^{-}$, respectively. At cathode, nickel oxyhydroxide is the active species undergoes reduction in presence of water $\left[2 \mathrm{H}_{2} \mathrm{O}\right]$ and electrons [2 $\left.\mathrm{e}^{-}\right]$to give nickel hydroxide $\left[2 \mathrm{Ni}(\mathrm{OH})_{2}\right]$ and hydroxyl ions $\left[4 \mathrm{OH}^{-}\right]$. At high currents with repeating discharges, the cycle life will be reduced $[29,30]$. The schematic view of NiMh battery is depicted in Figure 3.

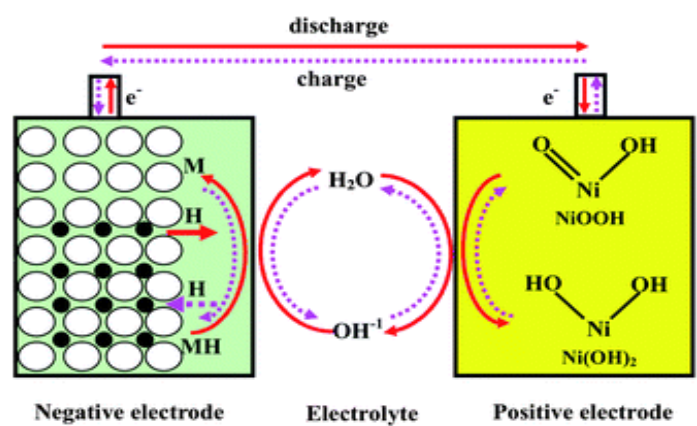

Figure 3. Schematic view of Ni-Mh battery

Overall reaction of nickel metal hydride battery at anode and cathode are expressed as [31],

At Anode: $\mathrm{MH}_{2}+2 \mathrm{OH}^{-} \leftrightarrow \mathrm{M}+2 \mathrm{H}_{2} \mathrm{O}+2 e^{-}$

At Cathode: $2 \mathrm{NiO}(\mathrm{OH})_{2}+2 \mathrm{H}_{2} \mathrm{O}+2 e^{-} \leftrightarrow 2 \mathrm{Ni}(\mathrm{OH})_{2}+4 \mathrm{OH}^{-}$

The capacity of NiMh batteries are: cell voltage is $1.2 \mathrm{~V}$, energy density is $140-300 \mathrm{Wh} / \mathrm{l}$, self discharge rate is $30 \% /$ month, specific energy is $60-120 \mathrm{Wh} / \mathrm{Kg}$, charge/discharge efficiency is $66 \%$, specific power is $250-1000 \mathrm{~W} / \mathrm{kg}$ and cycle durability is 500-1000 cycles [32]. Generally, these batteries are used in consumer 
electronics and utility/telecom backup. Typical cost of NiMh battery is $\$ 0.99 / \mathrm{Wh}$. The main benefits of NiMh batteries are better cycle life, high energy density and mature technology. However, the disadvantages are limited long-term potential for cost reductions and they are more expensive than lead-acid batteries [33].

\subsubsection{Nickel-cadmium (NiCd) battery}

$\mathrm{NiCd}$ is a rechargeable battery, where the positive electrode is nickel hydroxide $\left[\mathrm{Ni}(\mathrm{OH})_{2}\right]$, negative electrode is cadmium [Cd]. The electrolyte is a potassium hydroxide $[\mathrm{KOH}]$ which is alkaline in nature. The reaction is reversible as it is a rechargeable battery. The batteries have wide temperature range from $-40{ }^{\circ} \mathrm{C}$ to $70{ }^{\circ} \mathrm{C}$, which depends on the construction and has high self-discharge upto $20 \%$ of loss per month, batteries have energy density of 50-70 Wh/kg and also has relatively low cycle life of 2000-2500 cycles [34]. Schematic view of Ni-Cd battery is depicted in Figure 4. Chemical reactions of this battery are:

$$
\begin{aligned}
& \text { At Anode: } \mathrm{Cd}+2 \mathrm{OH}^{-} \leftrightarrow \mathrm{Cd}(\mathrm{OH})_{2}+2 e^{-} \\
& \text {At Cathode: } \mathrm{NiOOH}+\mathrm{H}_{2} \mathrm{O}+e^{-} \leftrightarrow \mathrm{Ni}(\mathrm{OH})_{2}+\mathrm{OH}^{-}
\end{aligned}
$$

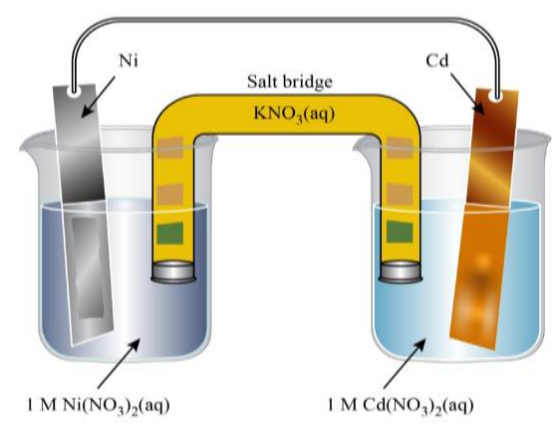

Figure 4. Schematic diagram of Ni-Cd battery

The capacity of NiCd battery has specific energy is $40-60 \mathrm{Wh} / \mathrm{Kg}$, energy density is $50-150 \mathrm{Wh} / \mathrm{l}$, specific power is $150 \mathrm{~W} / \mathrm{kg}$, charge/discharge efficiency is $70-90 \%$, self discharge rate is $10 \% / \mathrm{month}$, cycle durability is 2000 cycles and nominal cell voltage is $1.2 \mathrm{~V}$. The applications of $\mathrm{Ni}-\mathrm{Cd}$ batteries are utility/telecom backup and consumer electronics [35]. Cost of Ni-Cd battery is $\$ 1.50 / \mathrm{Wh}$. Ni-Cd have very toxic heavy metals which can contaminate the environment (soil), however there are recycle facilities that can safely dispose and result these batteries [36].

\subsection{Flow batteries}

These are electrochemical storage device which consists of two separate liquids flowing on either side of a membrane, where the chemical components dissolved in liquids gives the chemical energy contained within the system and it is separated by a membrane. Figure 5 depicts the schematic view of redox flow battery (RFB) with electrolyte tanks [37].

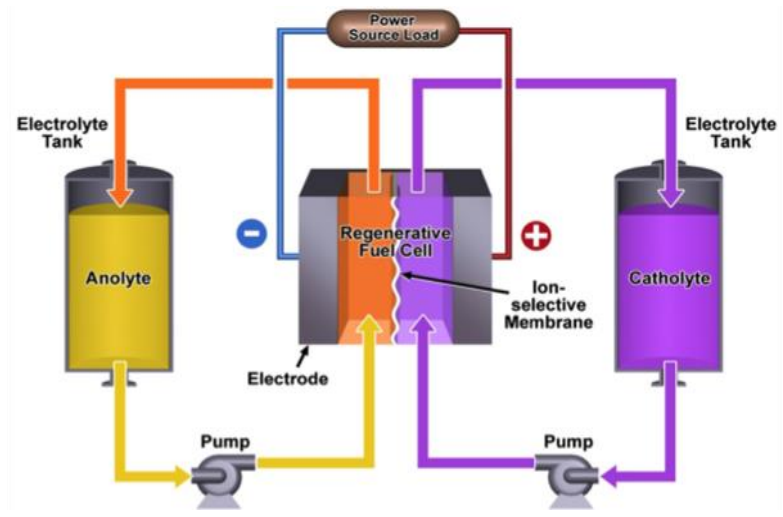

Figure 5. Schematic view of RFB system with electrolyte tanks 


\subsubsection{Vanadium redox battery (VRB)}

Main applications of VRB battery are backup power applications, small load leveling applications and peak shaving for transmission and distribution. Advantages of VRB are high power and energy densities, scalable for large applications, can be upgradeable easily and independent energy and power sizing. However, they are limited opportunities for standard sizes, quite expensive and it is a relatively new technology [38].

\subsubsection{Zinc bromine battery $(\mathrm{ZnBr})$}

The applications of $\mathrm{ZnBr}$ battery are backup power applications, small load levelling applications and peak shaving for transmission and distribution. Advantages of $\mathrm{ZnBr}$ batteries are high energy and power densities, scalable for large applications and partially independent energy and power sizing, whereas the disadvantages are safety hazard (corrosive and toxic materials), high maintenance cost and early-stage technology.

\subsection{Sodium-sulfur battery}

Sodium (Na) has high negative potential and has high specific capacity. Na salts are abundant in nature, they are cheap and even nontoxic. The rechargeable sodium-sulfur battery includes molten sulfur as its positive electrode, molten sodium as its negative electrode, and electrolyte is a solid beta alumina ceramic. At the temperature of $300{ }^{\circ} \mathrm{C}$ and $350{ }^{\circ} \mathrm{C}$ both sodium and sulfur are liquid, and solid electrolyte high conductivity of $\mathrm{Na}^{+}$. During discharge sodium emits electrons through the circuit, $\mathrm{Na}^{+}$ions flow through the electrolyte thus $\mathrm{Na}^{+}$ions reacts with sulfur by forming the sodium polysulphides. During the charge, the process is reversible as it effects the sodium polysulphide to decompose and $\mathrm{Na}^{+}$ions passes back through the electrolyte. The operating temperature of battery is usually kept at $300{ }^{\circ} \mathrm{C}$ to maintain the electrolyte in the liquid form. Sodium-sulfur batteries have energy density ranging from 150-240 W/kg, power density ranging from $150-230 \mathrm{~W} / \mathrm{kg}$ and they have long cycle life up to 5000-6000 cycles [39]. Schematic view of sodiumsulfur battery is depicted in Figure 6.

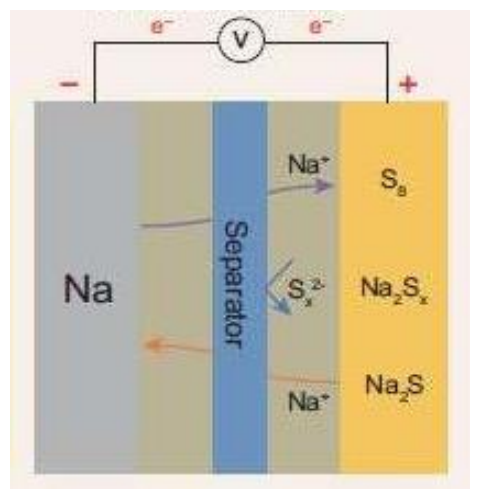

Figure 6. Schematic view of sodium-sulfur battery

The chemical reactions of this battery are:

At Anode: $5 \mathrm{~S}+2 \mathrm{Na} \leftrightarrow \mathrm{Na}_{2} \mathrm{~S}_{5}$

At Cathode: $3 \mathrm{Na}_{2} \mathrm{~S}_{5}+4 \mathrm{Na} \leftrightarrow 5 \mathrm{Na}_{2} \mathrm{~S}_{3}$

Applications of these batteries include electric vehicles, stationary applications, aerospace, small load levelling applications, peak shaving for transmission and upgrade deferral [40]. Main benefits of these batteries are long cycle life, high energy and power density and high efficiency. Whereas, the disadvantages are quite expensive and produces high temperatures (safety issues).

\section{CONCLUSION}

This paper has presented a detailed review of electrochemical batteries. The battery characteristics, application and its construction is described. An overview of various types of energy storage systems (ESSs) and the classification of storage systems has been presented in this paper. It also presents an extensive review on different electrochemical batteries, like lead-acid based, lithium-based, nickel-based, sodium-based and 
flow batteries for the purpose of using in electric vehicles in future trends. The technical and economical characteristics of various energy storage technologies are also presented in this paper. Applications, design, advantages and disadvantages of all the electrochemical batteries have been presented in this work.

\section{ACKNOWLEDGEMENTS}

This research work was supported by "Woosong University's Academic Research Funding-(2020-2021)".

\section{REFERENCES}

[1] Y. Liu, Q. Sun, W. Li, K. R. Adair, J. Li, X. Sun, "A comprehensive review on recent progress in aluminum-air batteries," Green Energy \& Environment, vol. 2, no. 3, pp. 246-277, 2017.

[2] M. H. Han, E. Gonzalo, G. Singh, T. Rojo, "A comprehensive review of sodium layered oxides: powerful cathodes for Na-ion batteries," Energy and Environmental Science, vol. 8, no. 1, pp. 81-102, 2015.

[3] C. Liu, Z. G. Neale, G. Cao, "Understanding electrochemical potentials of cathode materials in rechargeable batteries," Materialstoday, vol. 19, no. 2, pp. 109-123, 2016.

[4] Y. Li, and J. Lu, "Metal-Air Batteries: Will They Be the Future Electrochemical Energy Storage Device of Choice?," ACS Energy Letters, vol. 2, no. 6, pp. 1370-1377, 2017.

[5] J. Christensen, P. Albertus, R. S. Sanchez-Carrera, T. Lohmann, B. Kozinsky, R. Liedtke, J. Ahmed, and A. Kojic, "A Critical Review of Li/Air Batteries," Journal of Electrochemical Society, vol. 159, no. 2, pp. 1-30, 2012.

[6] L. Xia, L. Yu, D. Hu, G. Z. Chen, "Electrolytes for electrochemical energy storage," Materials Chemistry Frontiers, vol. 1, no. 4, pp. 584-618, 2017.

[7] M. S. Guney, and Y. Tepe, "Classification and assessment of energy storage systems," Renewable and Sustainable Energy Reviews, vol. 75, pp. 1187-1197, 2017.

[8] T. M. Masaud, K. Lee, P. K. Sen, "An overview of energy storage technologies in electric power systems: What is the future?," North American Power Symposium 2010, Arlington, TX, 2010, pp. 1-6.

[9] S. S. Zhang, "Status, opportunities, and challenges of electrochemical energy storage," Frontiers in Energy Research, vol. 1, no. 8, pp. 1-6, 2013.

[10] W. Sutopo, and E. A. Kadir, "Designing Framework for Standardization Case Study: Lithium-Ion Battery Module in Electric Vehicle Application," International Journal of Electrical and Computer Engineering (IJECE), vol. 8, no. 1, pp. 220-226, 2018.

[11] G. F. Frate, L. Ferrari, U. Desideri, "Energy storage for grid-scale applications: Technology review and economic feasibility analysis," Renewable Energy, vol. 163, pp. 1754-1772, 2021.

[12] X. Wang, X. Wei, J. Zhu, H. Dai, Y. Zheng, X. Xu, Q. Chen, "A review of modeling, acquisition, and application of lithium-ion battery impedance for onboard battery management," eTransportation, vol. 7, 2021.

[13] Z. Song, J. Li, J. Hou, H. Hofmann, M. Ouyang, J. Du, "The battery-supercapacitor hybrid energy storage system in electric vehicle applications: A case study," Energy, vol. 154, pp. 433-441, 2018.

[14] Q. Zhang, Q. F. Dong, M. S. Zheng, Z. W. Tian, "Electrochemical Energy Storage Device for Electric Vehicles," Journal of Electrochemical Society, vol. 158, no. 5, pp. 443-446, 2011.

[15] T. D. Atmaja, and Amin, "Energy Storage System Using Battery and Ultracapacitor on Mobile Charging Station for Electric Vehicle," Energy Procedia, vol. 68, pp. 429-437, 2015.

[16] T. K.Ying, X. P. Gao, W. K. Hu, F. Wu, D. Noréus, "Studies on rechargeable NiMH batteries," International Journal of Hydrogen Energy, vol. 31, no. 4, pp. 525-530, 2006.

[17] A. K. Shukla, S. Venugopalan, B. Hariprakash, "Nickel-Based Rechargeable Batteries," Journal of Power Sources, vol. 100 , no. 1-2, pp. 125-148, 2001.

[18] S. S. Reddy, "Optimal Scheduling of Thermal-Wind-Solar Power System with Storage," Renewable Energy, vol. 101, pp. 1357-1368, 2017.

[19] P. Albertus, J. Christensen, J. Newman, "Modeling Side Reactions and Nonisothermal Effects in Nickel MetalHydride Batteries," Journal of the Electrochemical Society, vol. 155, no. 1, pp. 48-60, 2008.

[20] Md. A. Zaman, Md. H. Rahaman, Md. S. Reza, Md. M. Islam, "Coordinated Control of Interconnected Microgrid and Energy Storage System," International Journal of Electrical and Computer Engineering (IJECE), vol. 8, no. 6, pp. 4781-4789, 2018.

[21] S. S. Reddy, “Optimal Power Flow with Renewable Energy Resources including Storage," Electrical Engineering, vol. 99 , no. 2, pp. 685-695, 2017.

[22] A. Ahmed, and T. Jiang, "Impact of compressed air energy storage system into diesel power plant with wind power penetration," International Journal of Electrical and Computer Engineering (IJECE), vol. 9, no. 3, pp. 1153-1560, 2019.

[23] R. Ye, D. Henkensmeier, S. J. Yoon, Z. Huang, D. K. Kim, Z. Chang, S. Kim, R. Chen, "Redox Flow Batteries for Energy Storage: A Technology Review," Journal of Electrochemical Energy Conversion and Storage, vol. 15, no. 1, pp. 1-21, 2017.

[24] S. S. Reddy, and C. M. Jung "Comparative analysis of storage techniques for a grid with renewable energy sources," International Journal of Engineering \& Technology, vol. 7, no. 3, pp. 970-976, 2018.

[25] E. Chemali, M. Preindl, P. Malysz, A. Emadi, "Electrochemical and Electrostatic Energy Storage and Management Systems for Electric Drive Vehicles: State-of-the-Art Review and Future Trends," IEEE Journal of Emerging and Selected Topics in Power Electronics, vol. 4, no. 3, pp. 1117-1134, 2016. 
[26] P. T. Moseley, and J. Garche, "Electrochemical Energy Storage for Renewable Sources and Grid Balancing," Elsevier, pp. 465-473, 2015.

[27] E. Chiodo, L. P. D. Noia, D. Lauria, "Stochastic modelling of electrochemical batteries for smart grids applications," 2014 International Symposium on Power Electronics, Electrical Drives, Automation and Motion, Ischia, 2014, pp. 1071-1076.

[28] S. S. Reddy, and C. M. Jung, "Overview of Energy Storage Technologies: A Techno-Economic Comparison," International Journal of Applied Engineering Research, vol. 12, no. 22, pp. 12872-12879, 2017.

[29] M. Sufyan, N. A. Rahim, M. M. Aman, C. K. Tan, and S. R. S. Raihan, "Sizing and applications of battery energy storage technologies in smart grid system: A review," Journal of Renewable and Sustainable Energy, vol. 11, no. 1, pp. 014105-1 - 014105-16, 2019.

[30] T. M. Gür, "Review of electrical energy storage technologies, materials and systems: challenges and prospects for large-scale grid storage," Energy and Environmental Science, vol. 11, no. 10, pp. 2696-2767, 2018.

[31] L. Yao, B. Yang, H. Cui, J. Zhuang, J. Ye, J. Xue, "Challenges and progresses of energy storage technology and its application in power systems," Journal of Modern Power Systems and Clean Energy, vol. 4, no. 4, pp. 519-528, 2016.

[32] S. S. Reddy, "Large scale electricity storage technology options for smart grid," International Journal of Engineering \& Technology, vol. 7, no. 2, pp. 635-639, 2018.

[33] M. C. Kocer, C. Cengiz, M. Gezer, D. Gunes, M. A. Cinar, B. Alboyaci, A. Onen, "Assessment of Battery Storage Technologies for a Turkish Power Network," Sustainability, vol. 11, no. 13, p. 3669, 2019.

[34] M. C. Such, and C. Hill, "Battery energy storage and wind energy integrated into the Smart Grid," 2012 IEEE PES Innovative Smart Grid Technologies (ISGT), Washington, DC, 2012, pp. 1-4.

[35] K. Zaghib, A. Mauger, C. M. Julien, "12-Rechargeable lithium batteries for energy storage in smart grids," Rechargeable Lithium Batteries, Woodhead Publishing Series in Energy, pp. 319-351, 2015.

[36] Rainer Bussar, et al., "Battery Energy Storage for Smart Grid Applications," Technical Report, EUROBAT, pp. 1-20, 2013.

[37] H. C. Hesse, M. Schimpe, D. Kucevic, A. Jossen, "Lithium-Ion Battery Storage for the Grid-A Review of Stationary Battery Storage System Design Tailored for Applications in Modern Power Grids," Energies, vol. 10, no. 12, pp. 1-42, 2017.

[38] S. S. Reddy, "Energy Storage Technologies for Smart Grid: A Comprehensive Review," Majlesi Journal of Electrical Engineering, vol. 14, No. 1, pp. 39-48, 2020.

[39] E. Hossain, D. Murtaugh, J. Mody, H. M. R. Faruque, M. S. Haque Sunny, N. Mohammad, "A Comprehensive Review on Second-Life Batteries: Current State, Manufacturing Considerations, Applications, Impacts, Barriers \& Potential Solutions, Business Strategies, and Policies," IEEE Access, vol. 7, pp. 73215-73252, 2019.

[40] B. V. Rajanna, and M. K. Kumar, "Comparison of one and two time constant models for lithium ion battery," International Journal of Electrical and Computer Engineering (IJECE), vol. 10, no. 1, pp. 670-680, 2020. 